\title{
Degradation behaviors of La-Mg-Ni-based metal hydride alloys: structural stability and influence on hydrogen storage performances
}

\author{
Yi-Ming Li ${ }^{1} \cdot$ Bao-Yu Duan ${ }^{2} \cdot$ Zhuo-Cheng Liu $^{1} \cdot$ Yang-Huan Zhang ${ }^{1} \cdot$ Hui-Ping Ren ${ }^{1}$
}

Received: 14 December 2017/Revised: 28 January 2018/Published online: 22 May 2018

(C) The Chinese Society for Metals and Springer-Verlag GmbH Germany, part of Springer Nature 2018

\begin{abstract}
The present work focuses on the structural stability upon hydrogenation of three typical La-Mg-Ni-based alloys: $\mathrm{La}_{2-}$ $\mathrm{MgNi}_{9}, \mathrm{La}_{3} \mathrm{MgNi}_{14}$ and $\mathrm{La}_{4} \mathrm{MgNi}_{19}$. Structural changes during gaseous and electrochemical cycles were characterized, and the influence of the structure distortion on the hydrogen storage properties was concerned. Hydrogen-induced amorphization (HIA) and disproportionation of the three alloys have occurred during both the gaseous and electrochemical cycles. Structural stability of the phase structures in the $\mathrm{La}-\mathrm{Mg}-\mathrm{Ni}$ system is found to follow the order: $\mathrm{LaNi}_{5}$ $>(\mathrm{La}, \mathrm{Mg})_{5} \mathrm{Ni}_{19}>(\mathrm{La}, \mathrm{Mg})_{2} \mathrm{Ni}_{7}>(\mathrm{La}, \mathrm{Mg}) \mathrm{Ni}_{3}>(\mathrm{La}, \mathrm{Mg}) \mathrm{Ni}_{2}$. HIA increases thermal stability of the metal hydrides and difficulty to dehydrogenation and leads to degradation of both the gaseous and electrochemical capacities. Interestingly, $\mathrm{La}_{2} \mathrm{MgNi}_{9}$ with poor stability presents elevated discharge capability even at $60{ }^{\circ} \mathrm{C}$ which can be attributed to increase in the hydrogen desorption capability and inhibition of the self-discharge induced by severe HIA at higher temperatures. In addition, HIA in the electrochemical reactions is obviously weaker than the extent during the gaseous cycles, which is mainly due to the slower hydrogenation speed. The development of HIA in the gaseous and electrochemical process is considered to follow the direct and gradual modes, respectively.
\end{abstract}

Keywords La-Mg-Ni-based alloys · Degradation behaviors · Hydrogen-induced amorphization · Electrochemical properties

\section{Introduction}

Superlattice $\mathrm{La}-\mathrm{Mg}-\mathrm{Ni}$-based hydrogen storage alloys are the next-generation negative electrode materials of nickel/ metal hydride battery for their excellent hydrogen storage ability [1-3]. Compared with the traditional $\mathrm{AB}_{5}$-type alloys, the La-Mg-Ni-based alloys present higher discharge capacity and lower self-discharge [4-7]. However,

Available online at http://link.springer.com/journal/40195

Electronic supplementary material The online version of this article (https://doi.org/10.1007/s40195-018-0744-2) contains supplementary material, which is available to authorized users.

Hui-Ping Ren

renhuiping@sina.com

1 Key Laboratory of Integrated Exploitation of Bayan Obo Multi-Metal Resources, Inner Mongolia University of Science and Technology, Baotou 014010, China

2 Analytical and Testing Center, Inner Mongolia University of Science and Technology, Baotou 014010, China electrochemical discharge capacities of those alloys decay rapidly during the long-term charge/discharge cycles. Numerous studies indicate that cycling stability of the La$\mathrm{Mg}-\mathrm{Ni}$ alloys is closely related to their chemical composition and phase constitution [4-11]. To improve the cycling stability further, it is, therefore, important to understand the relationship between the microstructure and the degradation mechanism of $\mathrm{La}-\mathrm{Mg}-\mathrm{Ni}$-based alloys.

It has been demonstrated that pulverization and corrosion are the main reasons attributing to capacity decay of the electrode alloys during the electrochemical charge/ discharge cycles [12-16]. In addition, capacity degradation of the metal hydrides is closely related to the structural changes during absorption/desorption cycles [17, 18]. The binary La-Ni-based alloys have already been reported to suffer hydrogen-induced amorphization (HIA) [19-22]. HIA worsens the reversible hydrogen storage capacity and leads to dramatic decrease in the electrochemical discharge capacity in $\mathrm{LaNi}_{3}$ and $\mathrm{La}_{5} \mathrm{Ni}_{19}[23,24]$. Though adding $\mathrm{Mg}$ is found to stabilize the crystal structure, HIA in $\mathrm{La}-\mathrm{Mg}-$ Ni-based compounds has also been detected in the previous 
works. Denys and Yartys investigated the HIA of $\mathrm{AB}_{3}$-type $\mathrm{La}_{3-x} \mathrm{Mg}_{x} \mathrm{Ni}_{9}$ alloys ( $x$ is below 0.7) [25]. Zhang et al. report that HIA took place in an $\mathrm{A}_{2} \mathrm{~B}_{7}$-type $\mathrm{La}_{1.6} \mathrm{Mg}_{0.4} \mathrm{Ni}_{7}$ alloy after 20 cycles of gaseous absorption/desorption process [26]. Our previous study demonstrated that HIA of both the $\mathrm{A}_{2} \mathrm{~B}_{7^{-}}$and $\mathrm{A}_{5} \mathrm{~B}_{19}$-type phases occurred in a multiphase $\mathrm{La}_{0.8} \mathrm{Mg}_{0.2} \mathrm{Ni}_{3.5}$ alloy after absorption/desorption cycles [27].

HIA is believed to be an important factor affecting the electrochemical cycling stability [23-27]; however, the influence of HIA on the degradation mechanisms of the $\mathrm{La}-\mathrm{Mg}-\mathrm{Ni}$ alloys is not well understood. HIA is closely related to the phase structure, but details of the effect of HIA on the hydrogen storage performances of various phases in the $\mathrm{La}-\mathrm{Mg}-\mathrm{Ni}$ system are also unclear. In our previous work, pulverization and corrosion behaviors of a series of $\mathrm{La}-\mathrm{Mg}-\mathrm{Ni}$ alloys have been studied [28]. However, it is still puzzled that $\mathrm{La}_{2} \mathrm{MgNi}_{9}$ with weaker corroded extent after electrochemical cycles presents poor cycling stability, suggesting that the structural deterioration beyond pulverization and corrosion should also be concerned. Thus, the structural changes of the three typical La-Mg-Ni-based alloys: $\mathrm{La}_{2} \mathrm{MgNi}_{9}, \mathrm{La}_{3} \mathrm{MgNi}_{14}$ and $\mathrm{La}_{4}$ $\mathrm{MgNi}_{19}$, were continuously studied in the present work. HIA behaviors and its influence on the hydrogen storage properties including the gaseous and electrochemical hydrogen storage capacity were discussed.

\section{Experimental}

The $\mathrm{La}_{2} \mathrm{MgNi}_{9}, \mathrm{La}_{3} \mathrm{MgNi}_{14}$ and $\mathrm{La}_{4} \mathrm{MgNi}_{19}$ alloys were prepared by induction levitation melting under argon atmosphere and followed by annealing at 870, 900 and $920{ }^{\circ} \mathrm{C}$ for $6 \mathrm{~h}$ in argon atmosphere, respectively. Details of the preparation, microstructural characterization and hydrogen storage properties measurements can be found in our previous work [28]. In order to refer to the microstructure and the original hydrogen storage properties, the X-ray diffraction (XRD) patterns of the three annealed alloys are also given in the present work for comparison, as shown in Fig. S1 in supplementary materials. Gas-solid absorption/desorption cycles were carried out by a Suzuki-2SDWIN PCT system (Sievert's type). Each cycle consists of absorption at $2 \mathrm{MPa}$ for $600 \mathrm{~s}$ and desorption by evacuating at $25{ }^{\circ} \mathrm{C}$ for $1200 \mathrm{~s}$. The alloy particles $(40-50 \mu \mathrm{m})$ were mixed with carbonyl nickel powder in a weight ratio of 1:5 and cold-pressed to form a pellet about $1 \mathrm{~g}$. The pellets were then packed in a $\mathrm{Ni}$ foam substrate and spot-welded with a Ni strip. The simulated three-electrode cell including a working electrode (metal hydride), a counter electrode $\left(\mathrm{NiOOH} / \mathrm{Ni}(\mathrm{OH})_{2}\right)$ and a reference electrode $(\mathrm{Hg} / \mathrm{HgO})$ was installed. The electrode pellets were firstly immersed in $6 \mathrm{~mol} \mathrm{~L}^{-1} \mathrm{KOH}$ aqueous solution for $1 \mathrm{~d}$, charged at a current density of $105 \mathrm{~mA} \mathrm{~g}^{-1}$ for $4 \mathrm{~h}$, followed by a rest for $10 \mathrm{~min}$, and then discharged at the same current density to the cutoff voltage of $-0.6 \mathrm{~V}$.

Powder diffraction of the alloy was collected by a Bruker-D8 Advance X-ray diffractometer with $\mathrm{Cu} K_{\alpha 1}$ radiation. Selected area electron diffraction (SAED) and energy-dispersive spectroscopy (EDS) were applied by means of a JEOL-2100 (LaB 6 ) and FEI-F20 (FEG) transmission electron microscopy (TEM) to examine the crystallographic and chemical information. For TEM samples, the bulk is firstly crushed into fine powder, and then, ultrasonic dispersion was performed in ethanol for $1800 \mathrm{~s}$. Several drops of the mixed liquid were laid on a carbon membrane support on the copper grid and dried in a vacuum oven. Thermal analysis of the cycled alloy was conducted by differential scanning calorimetric (DSC) and thermal gravimetric (TG) techniques using a NETZSCH STA449F3 thermal analyzer at heating rate of $10{ }^{\circ} \mathrm{C} \mathrm{min}^{-1}$ in the argon atmosphere.

\section{Results and discussion}

\subsection{Structural changes after gaseous absorption/ desorption cycles}

The XRD patterns of the alloys after gaseous absorption/ desorption by 10 cycles are shown in Fig. 1 . As can be clearly seen, the signal-to-background ratio of the cycled $\mathrm{La}_{2} \mathrm{MgNi}_{9}$ alloy decreases dramatically compared with the original alloy, indicating the poor crystallinity. In addition, most of the crystal diffraction peaks disappear, and the residual diffraction peaks are different from any of the original structures. It should be noted that diffraction peaks presenting in the cycled $\mathrm{La}_{2} \mathrm{MgNi}_{9}$ alloy can also be observed in the other two cycled alloys. In view of the fact that the coincident phase in the three alloys is $(\mathrm{La}, \mathrm{Mg})_{2} \mathrm{Ni}_{7}$ and $\mathrm{LaNi}_{5}$, but abundance of $\mathrm{LaNi}_{5}$ is too tiny to be concerned in the $\mathrm{La}_{2} \mathrm{MgNi}_{9}$ alloy, diffraction peaks presenting in the cycled $\mathrm{La}_{2} \mathrm{MgNi}_{9}$ alloy are speculated to be hydride of ( $\mathrm{La}, \mathrm{Mg})_{2} \mathrm{Ni}_{7}$. Compared with the reported structure of ( $\mathrm{La}, \mathrm{Mg})_{2} \mathrm{Ni}_{7} \mathrm{H}_{x}$ (ISCD-245831), it is found that if XRD peaks of the cycled $\mathrm{La}_{2} \mathrm{MgNi}_{9}$ alloy shift to the right side, they can match with the reported $(\mathrm{La}, \mathrm{Mg})_{2} \mathrm{Ni}_{7} \mathrm{H}_{x}$ except severe broadening (Fig. S2). Obviously, structural distortion of $(\mathrm{La}, \mathrm{Mg})_{2} \mathrm{Ni}_{7}$ is weaker than $(\mathrm{La}, \mathrm{Mg}) \mathrm{Ni}_{2}$ and $(\mathrm{La}, \mathrm{Mg}) \mathrm{Ni}_{3}$ whose diffraction peaks vanish completely after cycling. Right shift of the diffraction peaks of the hydride of $(\mathrm{La}, \mathrm{Mg})_{2} \mathrm{Ni}_{7}$ is attributed to the decrease in the lattice parameters since most of hydrogens have been released by pumping. 


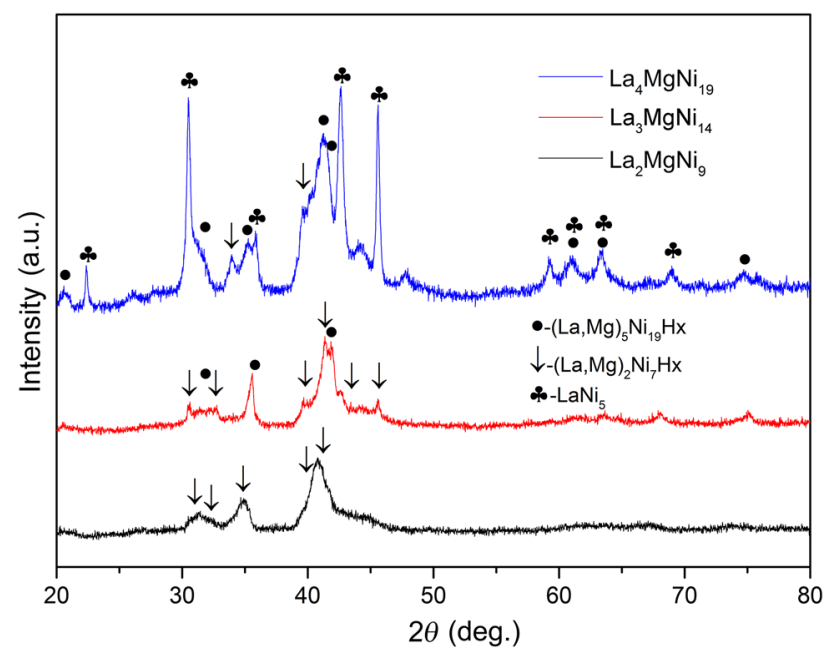

Fig. 1 XRD patterns of three alloys after gaseous cycling by 10 times
As to the cycled $\mathrm{La}_{3} \mathrm{MgNi}_{14}$ alloys, the diffraction pattern in our work is quite similar with that in Ref. [29], in which single-phase $\mathrm{La}_{3} \mathrm{MgNi}_{14}$ with $\mathrm{A}_{2} \mathrm{~B}_{7}$-type phase has been prepared by powder sintering method and then charge/discharge cycle. The phases of the cycled $\mathrm{La}_{3}$ $\mathrm{MgNi}_{14}$ alloys can be indexed including ( $\left.\mathrm{La}, \mathrm{Mg}\right)_{2} \mathrm{Ni}_{7} \mathrm{H}_{x}$ (ISCD-245831), (La, Mg) ${ }_{5} \mathrm{Ni}_{19} \mathrm{H}_{x}$ [30] and $\mathrm{LaNi}_{5}$, which are the same with the cycled $\mathrm{La}_{4} \mathrm{MgNi}_{19}$ alloys. The difference is the amount of $(\mathrm{La}, \mathrm{Mg})_{5} \mathrm{Ni}_{19} \mathrm{H}_{x}$, and crystal $\mathrm{LaNi}_{5}$ is pronounced due to the predominant abundance of these two phases in the $\mathrm{La}_{4} \mathrm{MgNi}_{19}$ alloys. In general, sharpness of the diffraction patterns of these three cycled alloys increases successively. Moreover, the percentages of the amorphous phase calculated by the Rietveld method using Maud software are confirmed to be 83.2, 57.5 and $22.3 \%$ for the cycled $\mathrm{La}_{2} \mathrm{MgNi}_{9}, \mathrm{La}_{3} \mathrm{MgNi}_{14}$ and $\mathrm{La}_{4}$ $\mathrm{MgNi}_{19}$ alloys, and the calculated profiles are shown in

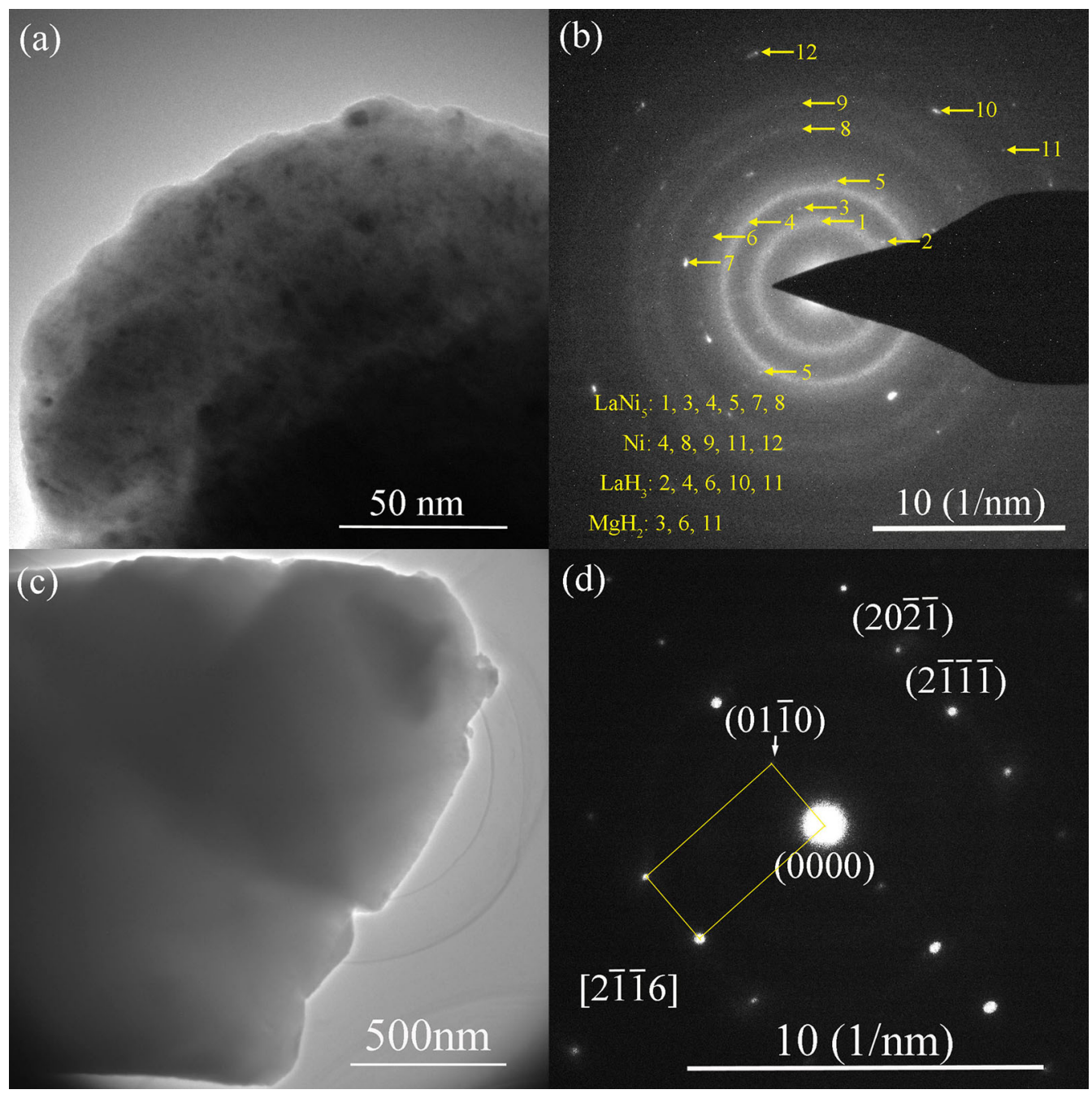

Fig. 2 TEM analysis of gaseously cycled $\mathrm{La}_{2} \mathrm{MgNi}_{9}$ alloy: a bright-field image of hydrogen-induced amorphization phase; b corresponding SAED pattern of $\mathbf{a} ; \mathbf{c}$ bright-field image of crystal $\mathrm{LaNi}_{5} ; \mathbf{d}$ SAED pattern of crystal $\mathrm{LaNi}_{5}$ 


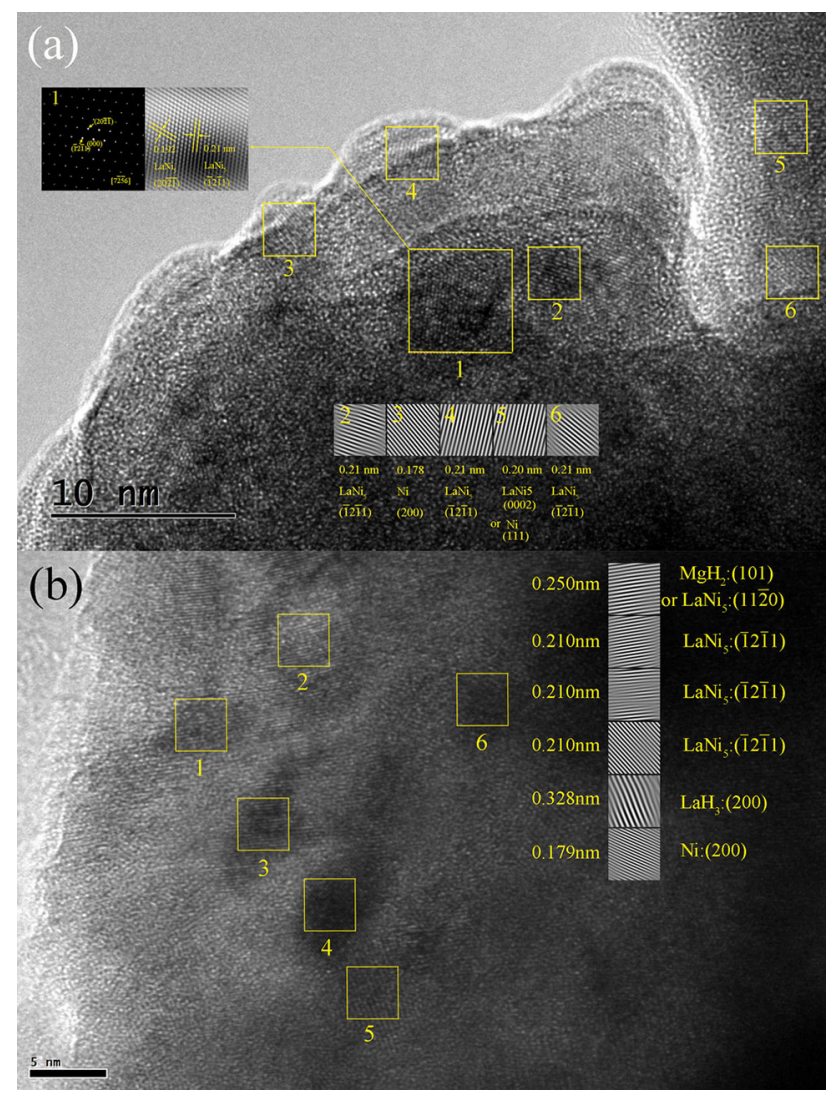

Fig. 3 HRTEM images of gaseously cycled $\mathrm{La}_{2} \mathrm{MgNi}_{9}$ alloy in region $1 \mathbf{a}$ and region $2 \mathbf{b}$

Fig. S3. These results illustrate that the structural stability against HIA follows the trend that $\mathrm{La}_{2} \mathrm{MgNi}_{9}<\mathrm{La}_{3}$ $\mathrm{MgNi}_{14}<\mathrm{La}_{4} \mathrm{MgNi}_{19}$. Our conclusion is also in accordance with the work by Liu et al., where amorphization of single-phase $\mathrm{La}_{2} \mathrm{MgNi}_{9}, \mathrm{La}_{3} \mathrm{MgNi}_{14}$ and $\mathrm{La}_{4} \mathrm{MgNi}_{19}$ alloy follows the same trend [29].

To confirm the crystal structure further, TEM analysis was conducted on the cycled $\mathrm{La}_{2} \mathrm{MgNi}_{9}$ alloy. Typical morphologies of the cycled samples are shown in Fig. 2. There are a large number of fine particles distributing in the matrix (Fig. 2a). SAED of the sample presents a mixed combination with halo- and ringlike patterns, indicating the amorphous and nanocrystalline nature of the sample. Identification of the diffraction rings confirms them to be $\mathrm{LaNi}_{5}, \mathrm{Ni}, \mathrm{MgH}_{2}$ and $\mathrm{LaH}_{3}$, and comparison of the measured and reported interplanar distances can be seen in Table S1. High-resolution TEM images (HRTEM) illustrate that abundant nanocrystalline particles with the size around 3-10 $\mathrm{nm}$ embed in an amorphous matrix, as shown in Fig. 3. Also, these particles identified by the interplanar distances are $\mathrm{LaNi}_{5}, \mathrm{Ni}, \mathrm{MgH}_{2}$ and $\mathrm{LaH}_{3}$. Moreover, EDS mapping in micro-area indicates the segregation of $\mathrm{La}$ and $\mathrm{Mg}$, as shown in Fig. 4. These aforementioned results demonstrate that both HIA and disproportionation have occurred in the cycled $\mathrm{La}_{2} \mathrm{MgNi}_{9}$ alloy, which is consistent with that reported by Zhang et al. [26]. These disproportionation phases cannot be detected by XRD due to their small size and low content.

Beyond the distorted phases, crystal $\mathrm{LaNi}_{5}$ can be found in the cycled $\mathrm{La}_{2} \mathrm{MgNi}_{9}$ alloy, as shown in Fig. 2 c. $\mathrm{LaNi}_{5}$ presents regular SAED spots and clean internal microstructure, indicating the good crystalline status. In addition, particle with a mixed microstructure composed of amorphous and larger crystalline (dozens of nanometers) is found to exist in the cycled $\mathrm{La}_{2} \mathrm{MgNi}_{9}$ alloy, as shown in Fig. 5 . SAED and HRTEM analysis indicates the crystal phase is $A_{2} B_{7}-3 R$ structure (Fig. 5c, d). Obviously, partial amorphization of ( $\mathrm{La}, \mathrm{Mg})_{2} \mathrm{Ni}_{7}$ has occurred after cycling. The results are in good agreement with the previous XRD characterization that crystal $(\mathrm{La}, \mathrm{Mg})_{2} \mathrm{Ni}_{7} \mathrm{H}_{x}$ with distorted structure can be detected in the cycled $\mathrm{La}_{2} \mathrm{MgNi}_{9}$ alloy. Though detailed structural changes of the $\mathrm{A}_{5} \mathrm{~B}_{19}$-type phase have not been caught in TEM for no $(\mathrm{La}, \mathrm{Mg})_{5} \mathrm{Ni}_{19}$ existing in the $\mathrm{La}_{2} \mathrm{MgNi}_{9}$ alloy, $(\mathrm{La}, \mathrm{Mg})_{5} \mathrm{Ni}_{19}$ is concluded to be similar to $(\mathrm{La}, \mathrm{Mg})_{2} \mathrm{Ni}_{7}$ that partial amorphization has occurred in view of the irregular XRD profile of the cycled $\mathrm{La}_{4} \mathrm{MgNi}_{19}$ alloy. The result accords well with our previous study and other researches that HIA has taken place on $(\mathrm{La}, \mathrm{Mg})_{5} \mathrm{Ni}_{19}$ phases after gas solid and electrochemical cycles [27, 29]. According to the above characterizations, structural stability toward HIA of the $\mathrm{La}-\mathrm{Mg}-\mathrm{Ni}$-based phases is believed to be as follows: $\mathrm{LaNi}_{5}>(\mathrm{La}, \mathrm{Mg})_{5} \mathrm{Ni}_{19}>(\mathrm{La}, \mathrm{Mg})_{2} \mathrm{Ni}_{7}>$ $(\mathrm{La}, \mathrm{Mg}) \mathrm{Ni}_{3}>(\mathrm{La}, \mathrm{Mg}) \mathrm{Ni}_{2}$.

\subsection{Influence of HIA on gas-solid properties}

Figure 6 shows the evolution of gaseous hydrogen absorption content of the three alloys during 10 cycles. It is clearly that hydrogen absorption capabilities decrease obviously, especially for the $\mathrm{La}_{2} \mathrm{MgNi}_{9}$ alloy. Capacity retentions are 52.9, 65.5 and $73.3 \%$, respectively, which keep consistent with trend of the structural stability of the three alloys. The capacity decrease concentrates in the previous two times, which is in good agreement with the previous studies that $\mathrm{La}-\mathrm{Mg}-\mathrm{Ni}$ phase transforms to amorphous just within one cycle [27].

Thermal analysis of the gaseously cycled alloys is displayed in Fig. 7. There are endothermic peaks around $130-150{ }^{\circ} \mathrm{C}$, accompanied with mass loss in all the three cycled alloys. The weight decreases are identical with values of the gaseous capacity decay, indicating dehydrogenation takes place at this temperature. This result demonstrates that HIA increases the thermal stability of the metal hydrides, leading to difficulty to dehydrogenation. In addition, endothermic peaks of the three alloys increase 

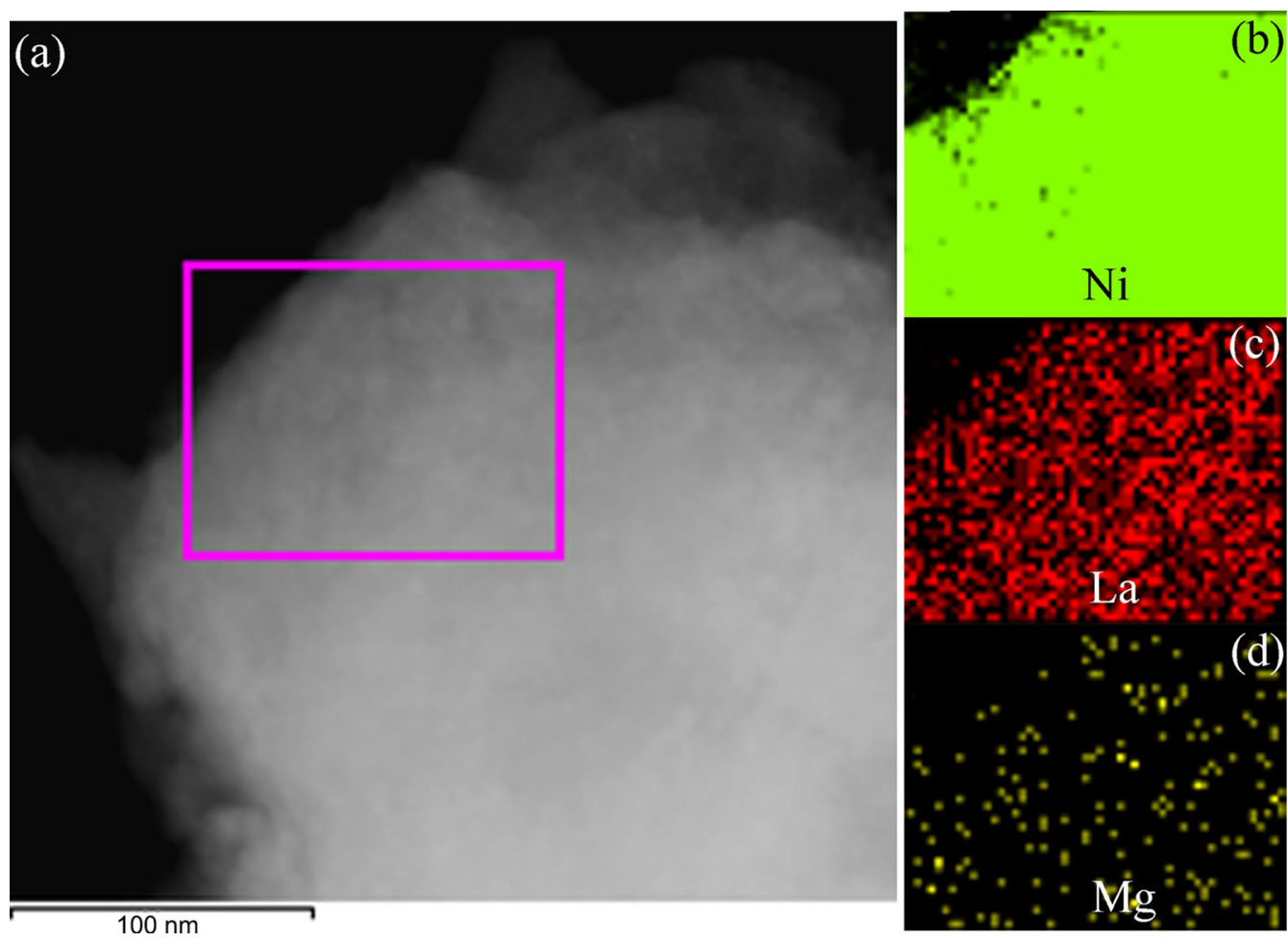

Fig. 4 STEM a and EDS-mapping of $\mathrm{Ni} \mathbf{b}, \mathrm{La} \mathbf{c}$ and $\mathrm{Mg} \mathbf{d}$ in gaseously cycled $\mathrm{La}_{2} \mathrm{MgNi}_{9}$ alloy

gradually, indicating that difficulty of dehydrogenation elevates severity of the structural distortion of the alloys.

Previous studies have found that crystal structure of La$\mathrm{Mg}-\mathrm{Ni}$ alloys suffered HIA can be recovered by annealing treatment [31, 32]. In the present work, we also perform annealing on the cycled $\mathrm{La}_{2} \mathrm{MgNi}_{9}$ alloy at $300{ }^{\circ} \mathrm{C}$ for $2 \mathrm{~h}$ in vacuum. The result shows that most of the crystal structure can be restored in this process, as shown in Fig. S4. But broadening of the diffraction pattern is still remained. The reason may be attributed to the short annealing time and existence of the disproportionation phases, which would influence the crystallization progress.

\subsection{Influence of HIA on electrochemical properties}

In order to illuminate influence of HIA on the electrochemical properties, discharge capacities of the gaseous cycled alloys were measured, and the results are listed in Table 1. It is found that discharge capacity of the cycled $\mathrm{La}_{2} \mathrm{MgNi}_{9}$ alloy is only $299 \mathrm{mAh} \mathrm{g}^{-1}$, which is far low than its original value $350 \mathrm{mAh} \mathrm{g}^{-1}$. The decrease also occurs in $\mathrm{La}_{3} \mathrm{MgNi}_{14}$, but the extent is less than $\mathrm{La}_{2} \mathrm{MgNi}_{9}$, while it is different for cycled $\mathrm{La}_{4} \mathrm{MgNi}_{19}$ alloy whose discharge capacity is even slightly improved than the original alloy. The result suggests that HIA has almost no impact on the electrochemical hydrogen storage capability of the $\mathrm{La}_{4} \mathrm{MgNi}_{19}$ alloy. Usually, the electrochemical discharge capacity is less than its gaseous hydrogen storage capability as only partial gaseous capacity can be used in the electrochemical reaction. For the $\mathrm{La}_{4} \mathrm{MgNi}_{19}$ alloy whose maximum gaseous capacity is $1.57 \mathrm{wt} \%$, the theoretical discharge capacity is $420 \mathrm{mAh} \mathrm{g}^{-1}$; however, the practical original discharge capacity is only $330 \mathrm{mAh} \mathrm{g}^{-1}$ with the utilization rate of about $78 \%$. The fact that the electrochemical discharge capacity of the cycled $\mathrm{La}_{4}$ $\mathrm{MgNi}_{19}$ alloy is almost unaffected can be explained for its better structural stability that the capacity retention after gaseous cycling $(73 \%)$ is similar to the utilization rate. It may be also ascribed to that more hydrogen can be released as the discharge time is longer (several hours) in the electrochemical reaction. Slight increase in the discharge capacity of the cycled $\mathrm{La}_{4} \mathrm{MgNi}_{19}$ alloy may be caused by refinement of the particle size by gaseous cycling which is benefit to the kinetics of the electrochemical reaction. In general, influence of HIA on the electrochemical properties accords well with the structural stability of the three alloys. And the reason $\mathrm{La}_{2} \mathrm{MgNi}_{9}$ presents poor cycling stability though the corrosion extent after electrochemical cycles is low and can be explained by its worse structural stability toward HIA.

Concerning to the aforementioned result that more hydrogen can be released at higher temperature, discharge capacity of the three alloys is tested at 40 and $60{ }^{\circ} \mathrm{C}$, and the results are also shown in Table 1 . Discharge capacities elevate at $40{ }^{\circ} \mathrm{C}$ for all the alloys, which are attributed to 


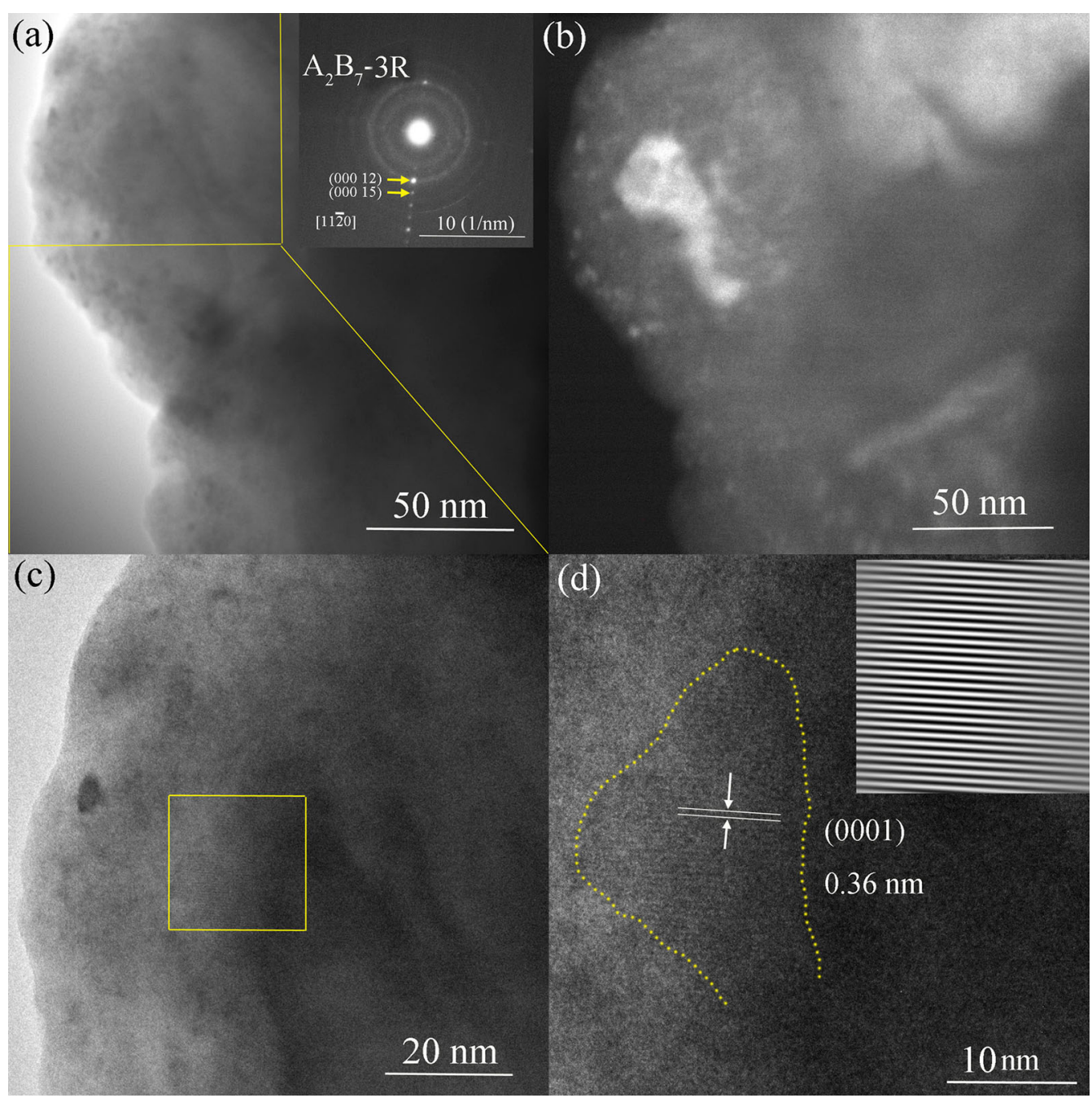

Fig. 5 Bright-field image (inset is SAED) a, dark-field image b and HRTEM images at low $\mathbf{c}$ and high $\mathbf{d}$ magnification of region where amorphous and crystal structure coexisting in gaseously cycled $\mathrm{La}_{2} \mathrm{MgNi}_{9}$ alloy

improvement of the electrochemical kinetics. At $60{ }^{\circ} \mathrm{C}$, discharge capacities of $\mathrm{La}_{3} \mathrm{MgNi}_{14}$ and $\mathrm{La}_{4} \mathrm{MgNi}_{19}$ decrease obviously. However, the $\mathrm{La}_{2} \mathrm{MgNi}_{9}$ alloy still presents improved discharge ability. To comprehend the phenomenon, pressure-composition-isotherm ( $P-C-$ T) curves of $\mathrm{La}_{2} \mathrm{MgNi}_{9}$ at 30 and $60{ }^{\circ} \mathrm{C}$ are tested as shown in Fig. 8a. The result indicates that the hydrogen desorption content at $60{ }^{\circ} \mathrm{C}$ is improved and the hysteresis decreases though the maximum hydrogen absorption capability decreases . Comparatively, $P-C-T$ curves of $\mathrm{La}_{4} \mathrm{MgNi}_{19}$ at 30 and $60{ }^{\circ} \mathrm{C}$ are also illustrated in Fig. $8 \mathrm{~b}$. Similar to $\mathrm{La}_{2} \mathrm{MgNi}_{9}$, the plateau increases and the hysteresis decreases, indicating the easiness for dehydrogenation of $\mathrm{La}_{4} \mathrm{MgNi}_{19}$ at higher temperatures. Nevertheless, elevation of the dehydrogenation ability by the temperature increasing is less evident for $\mathrm{La}_{4} \mathrm{MgNi}_{19}$. Adversely, the decrease in the hydrogen absorption ability leads to the decrease in the gaseous desorption content of
$\mathrm{La}_{4} \mathrm{MgNi}_{19}$ at $60{ }^{\circ} \mathrm{C}$. This result highlights elevation of the hydrogen desorption ability of $\mathrm{La}_{2} \mathrm{MgNi}_{9}$ with severe $\mathrm{HIA}$ at higher temperatures. No matter how, for both $\mathrm{La}_{2} \mathrm{MgNi}_{9}$ and $\mathrm{La}_{4} \mathrm{MgNi}_{19}$, changes of the discharge capacity at $60{ }^{\circ} \mathrm{C}$ are the same as that of the gaseous desorption content. Thus, increase in the discharge capacity of $\mathrm{La}_{2} \mathrm{MgNi}_{9}$ at $60{ }^{\circ} \mathrm{C}$ is ascribed to improvement of the hydrogen desorption content.

Usually, discharge capacity of $\mathrm{Ni} / \mathrm{MH}$ battery decreases at higher temperatures since charging of the electrode alloy becomes difficult and self-discharge is aggravated especially above $60{ }^{\circ} \mathrm{C}$. Evident decrease in the discharge capacity at around $60{ }^{\circ} \mathrm{C}$ has been reported in both the $\mathrm{AB}_{5}$-type and $\mathrm{La}-\mathrm{Mg}-\mathrm{Ni}$-based alloys [33-36], while it is exciting that $\mathrm{La}_{2} \mathrm{MgNi}_{9}$ with severe HIA presents elevated discharge capacity at $60{ }^{\circ} \mathrm{C}$. And thus a consideration that $\mathrm{AB}_{3}$-type alloys are likely be applied in the high-temperature $\mathrm{Ni} / \mathrm{MH}$ battery is suggested. This presumption is also 


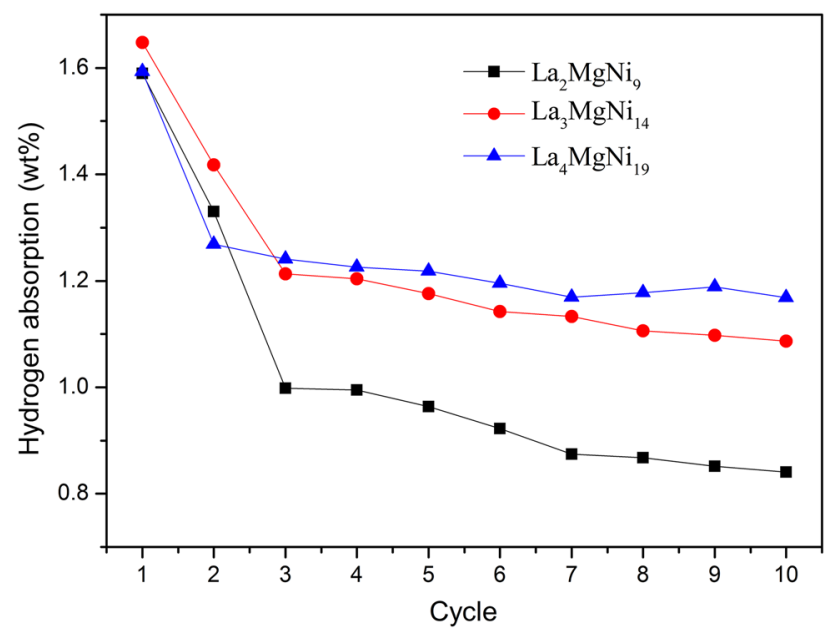

Fig. 6 Hydrogen absorption content of three alloys during gaseous cycling

based on the following other considerations except the elevated discharge capacity. One is the lower self-discharge of the $\mathrm{AB}_{3}$-type alloys. Among the $\mathrm{AB}_{3^{-}}, \mathrm{A}_{2} \mathrm{~B}_{7^{-}}$and $\mathrm{A}_{5} \mathrm{~B}_{19}$-type alloys, $\mathrm{AB}_{3}$-type alloy presents the lowest plateau which has been demonstrated in both $\mathrm{La}-\mathrm{Mg}-\mathrm{Ni}$ [28] and $\mathrm{Nd}-\mathrm{Mg}-\mathrm{Ni}$ systems [37]. It indicates that the $\mathrm{AB}_{3}$-type metal hydride possesses high thermodynamic stability which will lead to inhibition of the self-discharge at high temperatures. This consideration has been identified recently by [37] where self-discharge of the $\mathrm{AB}_{3^{-}}, \mathrm{A}_{2} \mathrm{~B}_{7^{-}}$ and $\mathrm{A}_{5} \mathrm{~B}_{19}$-type $\mathrm{Nd}-\mathrm{Mg}-\mathrm{Ni}$ alloys present a decreasing trend. Moreover, as mentioned above, HIA dramatically increases thermal stability of the metal hydride. Thus, inhibition of the self-discharge in the $\mathrm{AB}_{3}$-type alloys with severe HIA is considered to be more significant especially at higher temperatures. Another consideration of application of the $\mathrm{AB}_{3}$-type alloys on the high-temperature battery is that the amorphous alloys have been proposed to possess

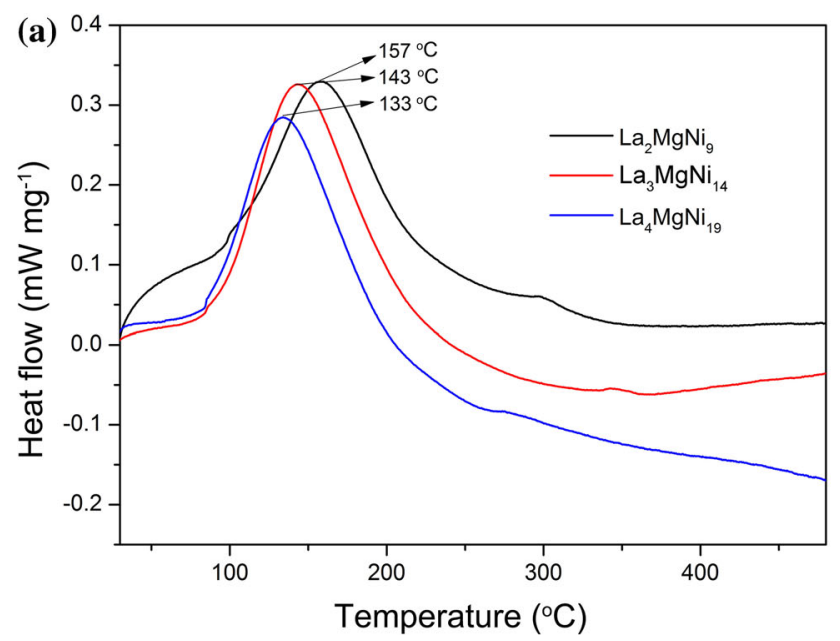

Fig. 7 DSC $\mathbf{a}$ and TG $\mathbf{b}$ curves of three alloys after gaseous cycling excellent anti-corrosion ability [38] which is also beneficial to the anti-corrosion capability of the electrode alloys at higher temperatures. Although thorough investigations are needed to further confirmation, it illuminates the development of high-temperature Ni/MH battery being possible especially for the $\mathrm{AB}_{3}$-type $\mathrm{La}-\mathrm{Mg}-\mathrm{Ni}$-based alloys, and the attempt is now in progress in our group.

\subsection{Difference of progress of HIA between gaseous and electrochemical reactions}

As discussed above, severe HIA significantly worsens the electrochemical discharge capacity, while a noteworthy phenomenon is that the electrochemical capacity decays of the three alloys are obviously lower than that in the gaseous process with the same cycles. For example, discharge capacity decay of the $\mathrm{La}_{2} \mathrm{MgNi}_{9}$ alloy after 100 electrochemical cycles is about $15 \%$, which is obvious lower than the value of the alloy after 10 times gaseous cycles (about 47\%). Theoretically, the alloys in the electrochemical process are also damaged by corrosion and pulverization except HIA; thus, the capacity decay is considered to be more notable with the same structural change. The slower degradation rate in the electrochemical reaction suggests that the structural deterioration is weaker than in the gaseous cycles.

To illustrate difference of the structural changes between the gaseous and electrochemical process, XRD patterns of the $\mathrm{La}_{2} \mathrm{MgNi}_{9}$ alloy after various gaseous and electrochemical cycles were measured and the profiles are displayed in Fig. 9. As is shown, there is no evident change after electrochemical cycles by 10 times, which is much less than that performed by gas-solid cycles with the same times. After 100 electrochemical cycles, remarkable

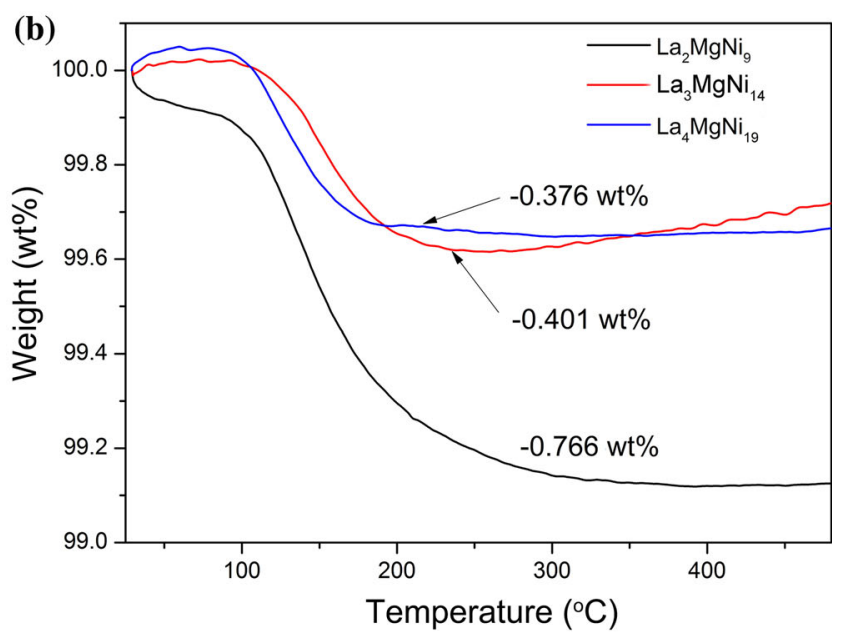


Table 1 Discharge capacities $\left(\mathrm{mAh} \mathrm{g}^{-1}\right)$ of three alloys under various conditions

\begin{tabular}{lllll}
\hline Alloy & DC $\left(30{ }^{\circ} \mathrm{C}\right)$ & DC $($ Gaseous phase activated $)$ & DC $\left(40{ }^{\circ} \mathrm{C}\right)$ & DC $\left(60{ }^{\circ} \mathrm{C}\right)$ \\
\hline $\mathrm{La}_{2} \mathrm{MgNi}_{9}$ & 350.8 & 299.1 & 365.9 & 370.8 \\
$\mathrm{La}_{3} \mathrm{MgNi}_{14}$ & 366.3 & 341.8 & 376.6 & 324.5 \\
$\mathrm{La}_{4} \mathrm{MgNi}_{19}$ & 332.1 & 340.6 & 336.4 & 282.4 \\
\hline
\end{tabular}

$D C$ the maximum discharge capacity
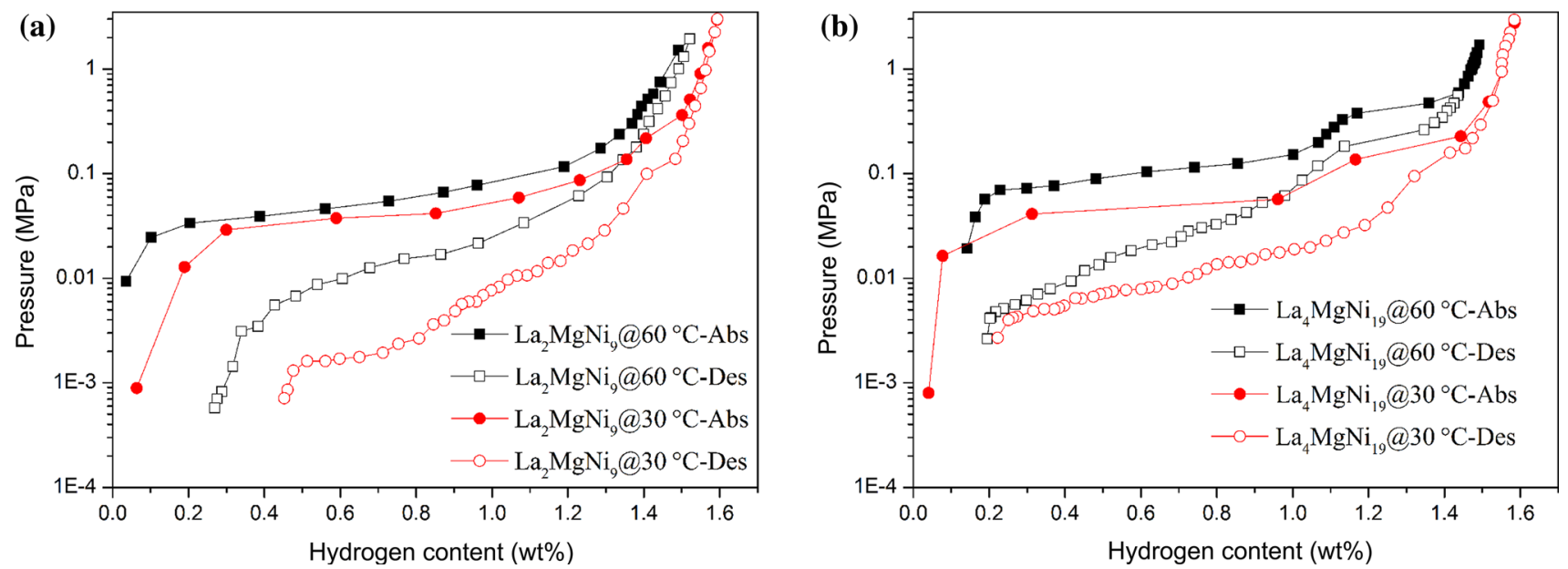

Fig. $8 P-C-T$ curves of $\mathrm{La}_{2} \mathrm{MgNi}_{9}$ a and $\mathrm{La}_{4} \mathrm{MgNi}_{19}$ b alloys under different temperatures (Abs and Des are abbreviations for absorption and desorption, respectively)

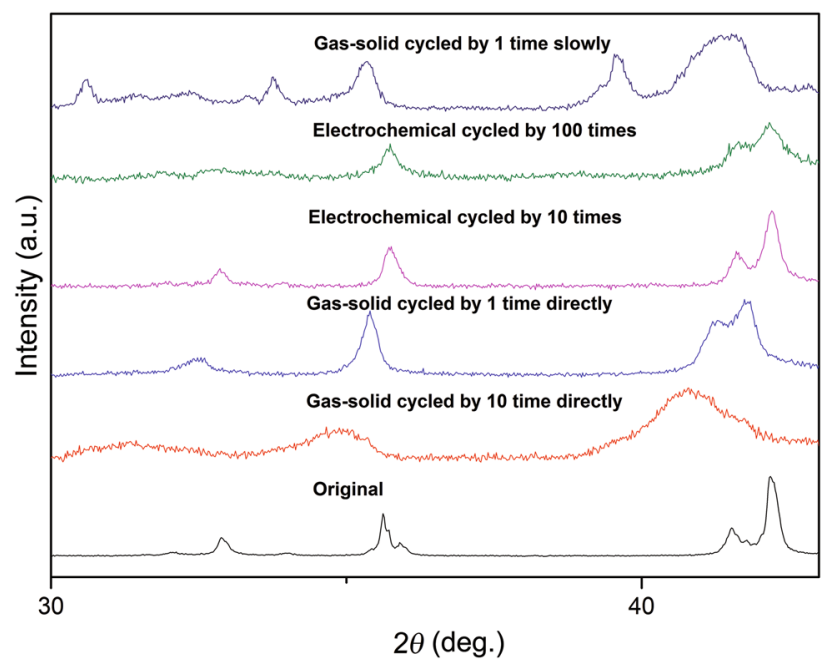

Fig. 9 Structural evolution of $\mathrm{La}_{2} \mathrm{MgNi}_{9}$ alloy under various hydrogenation processes

changes that broadening and absence of the diffraction peaks are visible, illustrating appearance of HIA. However, the structural distortion is weaker than the sample after gaseous cycles only for 10 times.

Furthermore, TEM analysis was also applied on the $\mathrm{La}_{2} \mathrm{MgNi}_{9}$ alloy after electrochemical cycled by 100 times. There are abundant corrosion products adhering on the surface of the sample as clearly shown in Fig. 10a. In addition, a large number of particles can be seen distributing in the matrix in the magnified image (Fig. 10b). This morphology is similar to the gaseous cycled sample (Figs. 2, 3, 4) which has decomposed to nanoparticles caused by disproportionation. SAED of the sample presents complex components including spots, rings and also halo patterns, as shown in Fig. 10c. Halo-like patterns indicate existence of amorphous, which is consistent with the results from XRD. Dark-field image of the marked spot is displayed in Fig. 10d, which is considered to be the corrosion products. Identification of the diffraction rings confirms them as the disproportionation and corrosion products. HRTEM of internal microstructure of this sample is shown in Fig. 11, from which $\mathrm{LaNi}_{5}, \mathrm{Ni}, \mathrm{LaH}_{3}$ and $\mathrm{MgH}_{2}$ can be identified, demonstrating again the occurrence of disproportionation.

The above results illustrate that HIA and disproportionation also take place in the electrochemical reaction, but evolution of the structural distortion is obviously slower than that in the gaseous reactions. Compared to structural changes during the gaseous process where HIA takes place just in less than two cycles, we conclude that development models of HIA in the gaseous and electrochemical process follow the direct and gradual mode, respectively. 

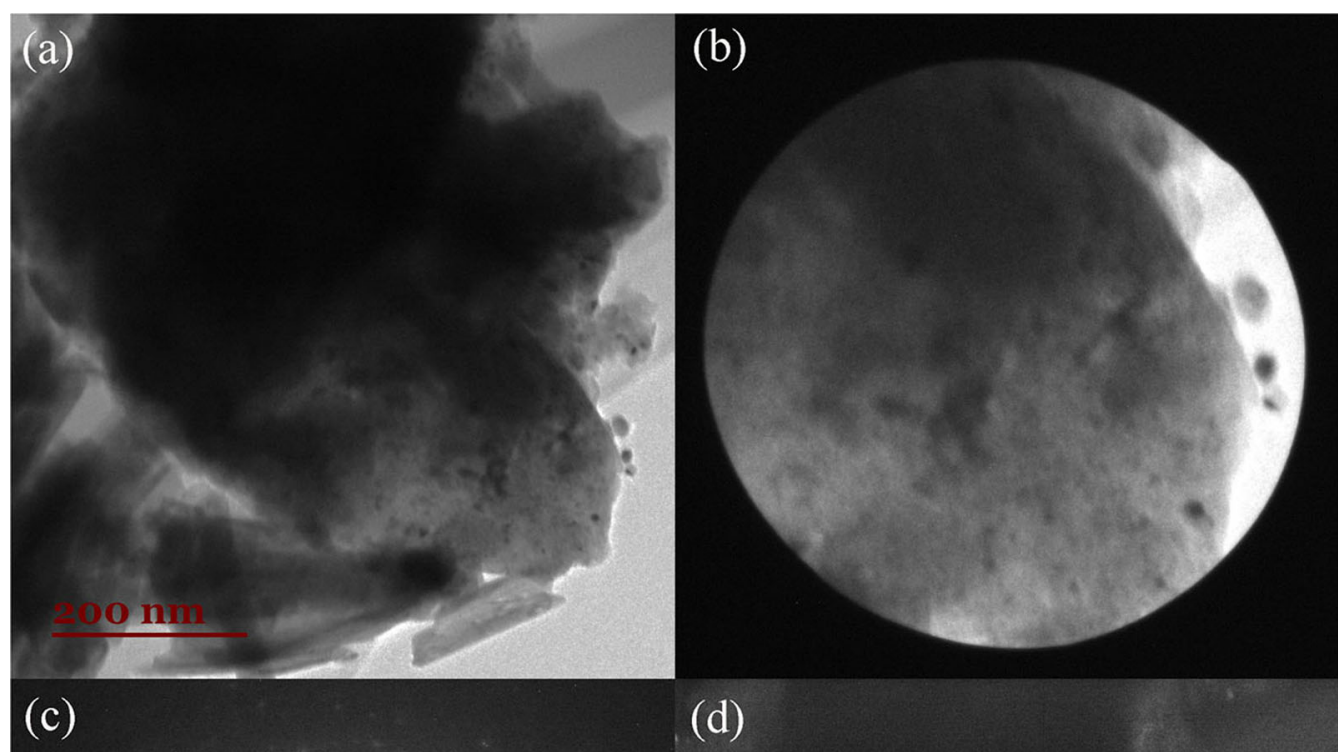

(d)
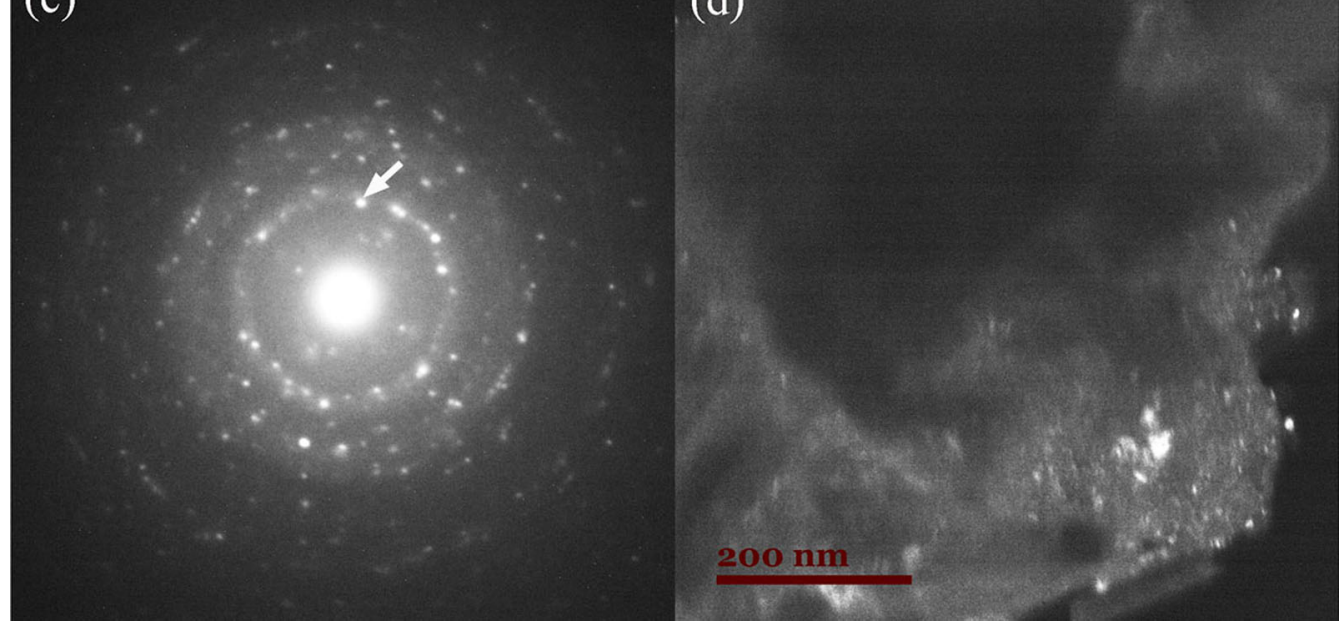

Fig. 10 TEM characterization of $\mathrm{La}_{2} \mathrm{MgNi}_{9}$ alloy after 100th electrochemical cycling: a bright-field image; $\mathbf{b}$ bright-field image of selected region for SAED; $\mathbf{c}$ SAED pattern; $\mathbf{d}$ bright-field image of diffraction spot in $\mathbf{c}$

In our previous work, HIA is found to take place with the increase in the hydrogen absorption content [27]. Thus, the slower structural change of the electrochemical cycling is believed to be correlated with the lower hydrogen concentration as the hydrogen absorption capability at higher part of the plateau cannot be used in the electrochemical reaction. Besides, the temperature and speed of the hydrogenation process are also considered to take into account.

High temperature can promote the short-range motion of atoms and may accelerate HIA which are considered to be thermally activated in some alloys [39-41]. There is also another kind mode of HIA which is strain induced beyond thermal energy [39]. As to the $\mathrm{La}-\mathrm{Mg}-\mathrm{Ni}$ phases, our previous study demonstrates that $\mathrm{HIA}$ of the $\mathrm{La}-\mathrm{Mg}-\mathrm{Ni}$ phases is considered to be an athermal process, which can be mobilized more intensely with the temperature decrease [27]. Moreover, the present work shows that more hydrogen can be released at higher temperatures. Thus, the extent of HIA of the $\mathrm{La}-\mathrm{Mg}-\mathrm{Ni}$ phases is believed to relieve at higher temperatures. It is known that the heat conduction of hydrogen storage alloys in the electrochemical reaction is faster than in gaseous process. Therefore, the temperature in the gas-solid reaction should be higher due to heat accumulation, while severe HIA in the gaseous reaction suggests that the temperature of the hydrogenation process is not the controlling fact toward HIA for the $\mathrm{La}-\mathrm{Mg}-\mathrm{Ni}$ phases.

Alternatively, we consider effect of the hydrogenation speed. Clearly, charging rate is fast in the gaseous reaction than that in the electrochemical process which usually takes several hours to complete a cycle. In order to confirm effect of the hydrogen absorption speed on the structural characters, a very slow hydrogenation process was adopted on the $\mathrm{La}_{2} \mathrm{MgNi}_{9}$ alloy with a pressure step of $0.02 \mathrm{MPa}$. Hydrogen absorption curve of the slow process is 


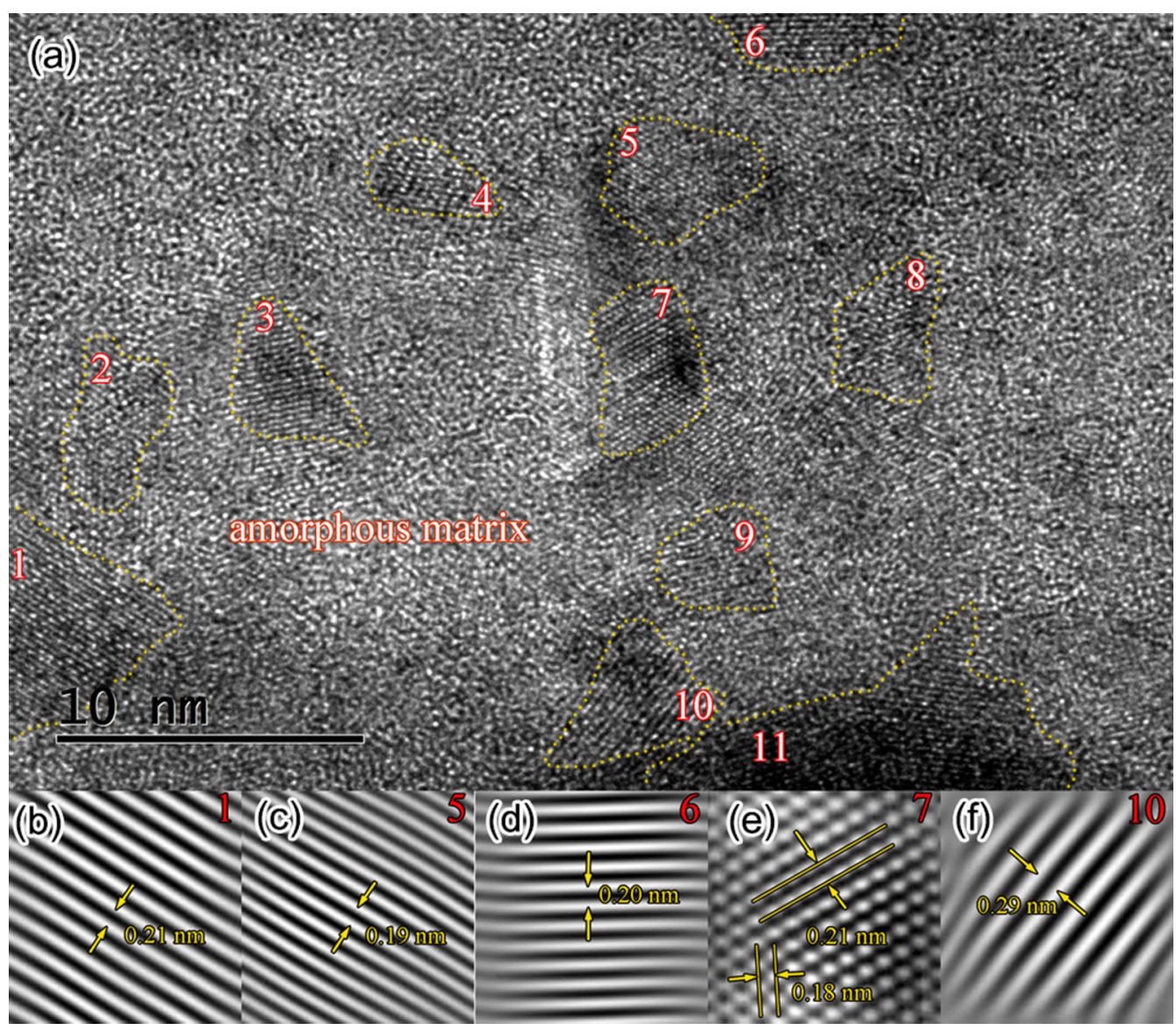

Fig. 11 HRTEM image of $\mathrm{La}_{2} \mathrm{MgNi}_{9}$ alloy after 100th electrochemical cycling $\mathbf{a}$ and corresponding fast Fourier transformation of area $1 \mathbf{b}$, area $5 \mathbf{c}$, area $6 \mathbf{d}$, area $7 \mathbf{e}$ and area $10 \mathbf{f}$

composed of nearly 100 data points, guaranteeing the very low hydrogenation rate, as shown in Fig. 12. The hydrogen absorption content is $1.5 \mathrm{wt} \%$, which is similar to that of the routine test. Thus, the influence of the hydrogen concentration could be ignored. From XRD of the slowly absorbed alloy shown in Fig. 9, it is obvious that the structural distortion is weaker than that of the sample by fast gaseous charging and also after 100 electrochemical cycles. New diffraction peaks beyond the original alloy indicate appearance of the crystal hydrides in the slow process.

Influence of the hydrogenation speed on the structural changes may be ascribed to the structural relaxation during the hydrogen absorption process. As studied previously, $\mathrm{HIA}$ in the $\mathrm{La}-\mathrm{Mg}-\mathrm{Ni}$-based alloys is caused by the severe distinct strain between the c-axis and a/b-axis upon hydrogen concentration [20-22]. An assumption is that self-adjustment of the crystal structure is easy to occur to compensate the anisotropic expansion in a more slow hydrogen absorption process. But further efforts also need to be performed. No matter how the result suggests that hydrogenation speed is important for the development of
HIA in the La-Mg-Ni-based alloys. Gradual evolution of HIA in the electrochemical charge/discharge process is ascribed to the slow hydrogenation speed.

The result also enlightens the possibility that adjusting of the charging rate may be benefit to the electrochemical stability of the $\mathrm{AB}_{3}$-type alloy with poor structural stability. To confirm this possibility, the $\mathrm{La}_{2} \mathrm{MgNi}_{9}$ alloy was slowly charged by $50 \mathrm{~mA} \mathrm{~g}^{-1}$, as displayed in Fig. 13. The capacity retention $\left(S_{100}\right)$ increased from $70.3 \%$ $\left(105 \mathrm{~mA} \mathrm{~g}^{-1}\right)$ to $73.8 \%\left(50 \mathrm{~mA} \mathrm{~g}^{-1}\right)$, demonstrating again that slow charging rate is benefit to the inhibition of HIA.

\subsection{Degradation behaviors and improvement strategies for cycling stability}

Combined with the results in Ref. [28] and our previous work, degradation characters of the $\mathrm{La}-\mathrm{Mg}-\mathrm{Ni}$ phases with increasing B-side stoichiometry are summarized as follows: (1) The intrinsic corrosion resistance presents an improved trend; (2) the intrinsic anti-pulverization ability decreases; and (3) the structural stability toward HIA is enhanced. 


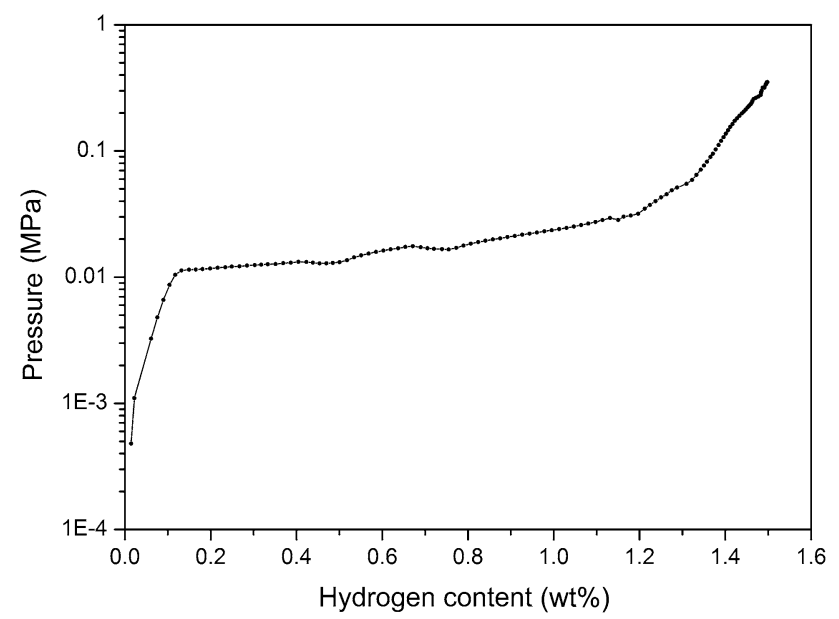

Fig. 12 Hydrogen absorption plateau of $\mathrm{La}_{2} \mathrm{MgNi}_{9}$ alloy by slow charge

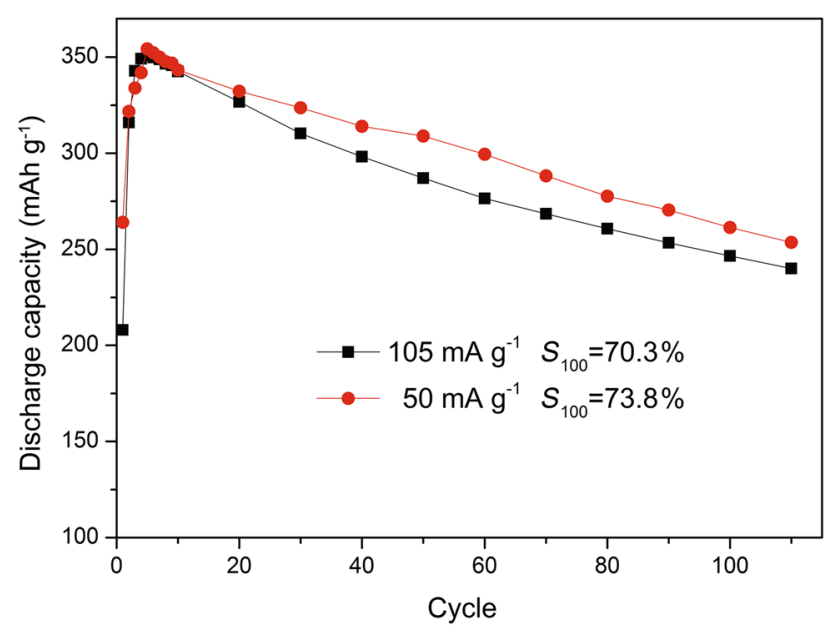

Fig. 13 Discharge capacities of $\mathrm{La}_{2} \mathrm{MgNi}_{9}$ alloy at different charging rates

Based on the above findings, it is concluded that HIA is not crucial to the $\mathrm{A}_{5} \mathrm{~B}_{19}$-type alloy since capacity deterioration caused by HIA can be ignored. For the $\mathrm{A}_{2} \mathrm{~B}_{7}$-type alloys, the influence of HIA is faint, but it still cannot be neglected especially during the extremely long-term cycles. Enhancement of the structural stability is more significant for the $\mathrm{AB}_{3}$-type alloy, and large decay of the electrochemical discharge capacity will be induced by HIA in this alloy. In addition, improvement of the anti-pulverization ability is necessary for all the alloys. But it is more urgent for the $\mathrm{A}_{5} \mathrm{~B}_{19}$-type alloy. The other significance is promotion of the corrosion resistance since evident corrosion exists in all the $\mathrm{La}-\mathrm{Mg}-\mathrm{Ni}$ alloys after the electrochemical cycles, while there is no doubt that anti-corrosion ability during the electrochemical reaction is more essential to the $\mathrm{AB}_{3}$-type alloy. A comparison of the degradation characters of the $\mathrm{AB}_{3^{-}}, \mathrm{A}_{2} \mathrm{~B}_{7^{-}}$and $\mathrm{A}_{5} \mathrm{~B}_{19}$-type $\mathrm{La}-\mathrm{Mg}-\mathrm{Ni}$ based alloys is schematically illustrated in Fig. 14. Overall, our results demonstrate that the $\mathrm{A}_{2} \mathrm{~B}_{7}$-type alloy is more satisfying for the electrochemical cycling stability though both the anti-pulverization and anti-corrosion ability are not the best yet. This opinion is also in consistent with other researchers $[42,43]$. Nevertheless, the $\mathrm{A}_{2} \mathrm{~B}_{7}$-type alloys without alloying still need the improvement of the cycling stability to meet the practical application.

For further development of the $\mathrm{La}-\mathrm{Mg}-\mathrm{Ni}$-based alloys, several approaches for the improvement of the cycling stability and the challenges are also discussed and summarized here.

\subsubsection{Elemental substitution}

Substitution by the A- or B-side elements has been extensively studied in the last decays and is confirmed to be exactly effective for the enhancement of the electrochemical properties [2, 3, 44]. Especially, substitution of La and $\mathrm{Mg}$ is found to be more favorable for the cycling stability with less decrease in the discharge capacity. A $\mathrm{La}_{0.95}$ $\mathrm{Sm}_{0.66} \mathrm{Mg}_{0.40} \mathrm{Ni}_{6.25} \mathrm{Al}_{0.42} \mathrm{Co}_{0.32}$ alloy with high content of $\mathrm{A}_{2} \mathrm{~B}_{7}$-type phase $(96.3 \%)$ exhibits excellent cycling stability of retaining ratio of $80 \%$ after 239 cycles at $1 \mathrm{C}$ [45]. Adding $\mathrm{Sm}$ is found to enhance the anti-pulverization stability due to the decrease in the cell volume upon hydrogen and refinement of the grain size $[45,46]$. Sm is also reported to be beneficial to the structural stability where $\mathrm{Sm}_{2} \mathrm{Co}_{7}$ presents good stability after 50 gas solid cycles [47]. $\mathrm{Pr}_{4} \mathrm{MgNi}_{19}$ alloy has been reported to make dense corrosion-resistant protective layer and lower lattice mismatch which contributes to the superior cycling stability than $\mathrm{La}_{4} \mathrm{MgNi}_{19}$ alloy [48]. Besides the rare earth elements, the content of $\mathrm{Mg}$ is very important to the hydrogen storage performances. Addition of $\mathrm{Mg}$ is a key point to increase the structure stability and suppress HIA [20-22]. Inversely, addition of $\mathrm{Mg}$ leads to difficulty to fabrication of alloy due to easy evaporation of $\mathrm{Mg}$ and also dramatically decreases the corrosion resistance [2, 3, 28]. To solve this problem, Mg-free $\mathrm{La}-\mathrm{Y}-\mathrm{Ni}$ alloys have been developed recently as the electrode alloys with better discharge capacity and cycling stability than the $\mathrm{AB}_{5}$-type alloys [43, 49].

Although dramatic positive influence on the electrochemical properties can be brought by alloying substitution, adding of different elements is quite complicated including changes of the chemical composition, phase constitution, grain size and micromorphology. It also should be noted that contradiction between the cycling stability and discharge capacity or high-rate dischargeability (HRD) after alloying still needs to be further improved and systematical studied. 


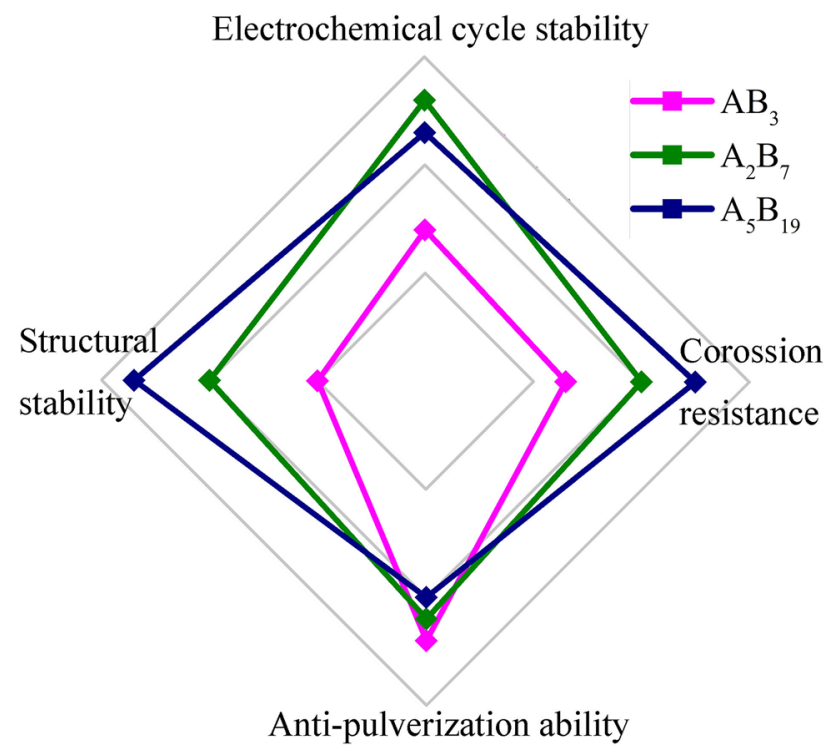

Fig. 14 Schematic illustration of degradation characters of $\mathrm{AB}_{3^{-}}$,

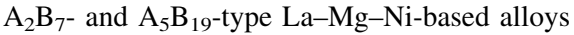

\subsubsection{Regulation of phase constitution}

Substantial works have demonstrated that hydrogen storage performances of the $\mathrm{La}-\mathrm{Mg}-\mathrm{Ni}$ alloys are closely related to the microstructure including the crystal structure and phase abundance $[2,3,44]$. The $\mathrm{A}_{2} \mathrm{~B}_{7}$-type phase has long been considered to be suitable for the electrochemical application. An $\mathrm{A}_{2} \mathrm{~B}_{7}$ single-phase $\mathrm{La}_{1.6} \mathrm{Mg}_{0.4} \mathrm{Ni}_{7}$ alloy presents excellent cycling stability with the capacity retention of $84 \%$ after 100 cycles [26]. The $A_{5} B_{19}$ phase is also reported to be favorable as the negative electrode. For example, a $\mathrm{La}_{0.78} \mathrm{Mg}_{0.22} \mathrm{Ni}_{3.73}$ alloy with single-phase $\mathrm{A}_{5} \mathrm{~B}_{19}$-type structure presents excellent cycling stability that the capacity retention reaches to $85 \%$ after 100 electrochemical cycles [50].

A complicated matter is that most of the $\mathrm{La}-\mathrm{Mg}-\mathrm{Ni}$ alloys have multi-phase microstructure. In general, highcontent $\mathrm{A}_{2} \mathrm{~B}_{7}$ phase is suggested to be significant to improvement of the cycling stability which has been demonstrated in Refs. [1, 51, 52]. In addition, minor $\mathrm{A}_{5} \mathrm{~B}_{19}$-type phase adding in the $(\mathrm{La}, \mathrm{Mg})_{2} \mathrm{Ni}_{7}$ matrix has also been reported to be beneficial to the cycling stability [53], while the existence of $\mathrm{LaNi}_{5}$ phase is found to be harmful to the cycling stability in a series of $\mathrm{La}_{3} \mathrm{MgNi}_{19}$ alloys [54]. Our results demonstrate that $\mathrm{LaNi}_{5}$ is more brittle and easy to crack formation [28]. Overall, microstructure with $\mathrm{A}_{2} \mathrm{~B}_{7^{-}}$and $\mathrm{A}_{5} \mathrm{~B}_{19}$-type phase is more desirable from the view point of the practical application, which significantly depends on the composition design and preparation process.

\subsubsection{Grain refinement}

Grain refinement is not only beneficial to the kinetics property but also the pulverization resistance for the hydrogen storage alloys. Grain refinement can be achieved by element substitution such as $\mathrm{Sm}[45,46,55]$ and preparation method such as rapid quenching [28]. Zhang et al. found that the cycling stability of the RE-Mg-Ni-based alloys prepared by rapid quenching can be extensively improved due to the enhanced anti-pulverization ability of the fine microstructure [56-59]. However, the drawback of rapid quenching is the decrease in the discharge capacity and HRD. Significant improvement of $\mathrm{HRD}$ has been reported in a rapid quenched $\mathrm{La}_{4} \mathrm{MgNi}_{19}$ alloy followed by annealing [60].

\section{Conclusion}

The structural changes and influence on the hydrogen storage properties of $\mathrm{La}_{2} \mathrm{MgNi}_{9}, \mathrm{La}_{3} \mathrm{MgNi}_{14}$ and $\mathrm{La}_{4} \mathrm{MgNi}_{19}$ alloys during the gaseous and electrochemical cycles were investigated. Some results are summarized as follows:

1. ( $\mathrm{La}, \mathrm{Mg}) \mathrm{Ni}_{2}$ and ( $\left.\mathrm{La}, \mathrm{Mg}\right) \mathrm{Ni}_{3}$ phases can completely transform to amorphous after gaseous cycling, while only partial amorphization has occurred in $(\mathrm{La}, \mathrm{Mg})_{2}$ $\mathrm{Ni}_{7}$ and (La, $\left.\mathrm{Mg}\right)_{5} \mathrm{Ni}_{19}$. In addition, disproportionation that the cycled ( $\mathrm{La}, \mathrm{Mg}) \mathrm{Ni}_{2}$ and $(\mathrm{La}, \mathrm{Mg}) \mathrm{Ni}_{3}$ decomposed into $\mathrm{LaNi}_{5}, \mathrm{Ni}, \mathrm{MgH}_{2}$ and $\mathrm{LaH}_{3}$ has been detected. The structural stability against HIA follows the trend that $\mathrm{LaNi}_{5}>(\mathrm{La}, \mathrm{Mg})_{5} \mathrm{Ni}_{19}>(\mathrm{La}, \mathrm{Mg})_{2} \mathrm{Ni}_{7}$ $>(\mathrm{La}, \mathrm{Mg}) \mathrm{Ni}_{3}>(\mathrm{La}, \mathrm{Mg}) \mathrm{Ni}_{2}$.

2. HIA leads to significant decrease in the gaseous absorption content of the alloys, due to the increase in the thermal stability and difficulty to dehydrogenation of the hydrides. HIA is also found to worsen the electrochemical discharge capacity, and decrease in the discharge capacity accords well with the structural stability of the three alloys. Thus, the poor cycling stability of $\mathrm{La}_{2} \mathrm{MgNi}_{9}$ is ascribed to its worse structural stability against HIA though the corrosion extent after the electrochemical cycling is lower. In addition, it is found that more hydrogen can be released at higher temperatures. Improvement of the discharge capacity in $\mathrm{La}_{2} \mathrm{MgNi}_{9}$ is achieved even when the temperature reaches to $60{ }^{\circ} \mathrm{C}$ due to improvement of the dehydrogenation ability and inhibition of the self-discharge.

3. HIA and disproportionation also take place after certain cycles in the electrochemical reaction, but evolution of the structural destroy is obviously slower than that during the gaseous reactions. The development of HIA in the gaseous and electrochemical process is considered to follow the direct and gradual 
modes, respectively. Structural distortion at slow absorption rate is obviously weaker than that by fast charging, which is considered to attribute to the slower structural change in the electrochemical cycling.

Acknowledgements This work was supported financially by the National Natural Science Foundation of China (No. 51761032) and the University Foundation of Inner Mongolia (No. NJZZ18142).

\section{References}

[1] S. Yasuoka, Y. Magari, T. Murata, T. Tadayoshi, J. Ishida, H. Nakamura, T. Nohma, K. Masaru, J. Power Sources 156, 662 (2006)

[2] Y.F. Liu, Y.H. Cao, L. Huang, M.X. Gao, H.G. Pan, J. Alloys Compd. 509, 675 (2011)

[3] J.J. Liu, S.M. Han, Y. Li, L. Zhang, Y.M. Zhao, S.Q. Yang, B.Z. Liu, Int. J. Hydrog. Energy 41, 20261 (2016)

[4] B. Liao, Y.Q. Lei, G.L. Lu, L.X. Chen, H.G. Pan, Q.D. Wang, J. Alloys Compd. 356-357, 746 (2003)

[5] J.J. Liu, S.M. Han, Y. Li, S.Q. Yang, W.Z. Shen, L. Zhang, Y. Zhou, J. Alloys Compd. 552, 119 (2013)

[6] X. Cai, F.S. Wei, F.N. Wei, H.H. Lu, Acta Metall. Sin. (Engl. Lett.) 29, 614 (2017)

[7] Y. Zhang, F.S. Wei, J.N. Xiao, X. Cai, Acta Metall. Sin. (Engl. Lett.) 30, 1033 (2017)

[8] B. Liao, Y.Q. Lei, L.X. Chen, G.L. Lu, H.G. Pan, Q.D. Wang, J. Power Sources 129, 358 (2004)

[9] F.L. Zhang, Y.C. Luo, J.P. Chen, R.X. Yan, J.H. Chen, J. Alloys Compd. 430, 302 (2007)

[10] F. Li, K. Young, T. Ouchi, M.A. Fetcenko, J. Alloys Compd. 471, 371 (2009)

[11] W.K. Hu, R.V. Denys, C.C. Nwakwuo, T. Holm, J.P. Maehlen, J.K. Solberg, V.A. Yartys, Electrochim. Acta 96, 27 (2013)

[12] T. Sakai, K. Oguro, H. Miyamura, N. Kuriyama, A. Kato, H. Ishikawa, J. Less-Common Met. 161, 193 (1990)

[13] D. Chartouni, F. Meli, A. Züttel, K. Gross, L. Schlapbach, J. Alloys Compd. 241, 160 (1996)

[14] Y.F. Liu, H.G. Pan, Y.J. Yue, X.F. Wu, N. Chen, Y.Q. Lei, J. Alloys Compd. 395, 291 (2005)

[15] X.Z. Sun, H.G. Pan, M.X. Gao, R. Li, Y. Lin, S. Ma, Trans. Nonferrous Met. Soc. China 16, 8 (2006)

[16] Y.H. Zhang, D.L. Zhao, B.W. Li, H.P. Ren, X.P. Dong, X.L. Wang, Trans. Nonferrous Met. Soc. China 17, 816 (2007)

[17] R.C. Bowman, C.H. Luo, C.C. Ahn, C.K. Witham, B. Fultz, J. Alloys Compd. 217, 185 (1995)

[18] Y.M. Li, H.W. Zhang, Y.H. Zhang, H.P. Ren, Rare Met. 36, 101 (2017)

[19] J. Chen, H.T. Takeshita, H. Tanaka, N. Kuriyama, T. Sakai, I. Uehara, M. Haruta, J. Alloys Compd. 302, 304 (2000)

[20] R.V. Denys, B. Riabov, V.A. Yartys, R.G. Delaplane, M. Sato, J. Alloys Compd. 446-447, 166 (2007)

[21] R.V. Denys, V.A. Yartys, M. Sato, A.B. Riabov, R.G. Delaplane, J. Solid State Chem. 180, 2566 (2007)

[22] R.V. Denys, A.B. Riabov, V.A. Yartys, M. Sato, R.G. Delaplane, J. Solid State Chem. 181, 812 (2008)

[23] W. Wang, Y.G. Chen, C.L. Wu, Rare Met. Mater. Eng. 40, 2080 (2011)

[24] A. Férey, F. Cuevas, M. Latroche, B. Knosp, P. Bernar, Electrochim. Acta 54, 1710 (2009)

[25] R.V. Denys, V.A. Yartys, J. Alloys Compd. 509s, S540 (2011)

[26] L. Zhang, S.M. Han, D. Han, Y. Li, X. Zhao, J.J. Liu, J. Alloys Compd. 268, 575 (2014)
[27] Y.M. Li, H.P. Ren, Y.H. Zhang, Z.C. Liu, H.W. Zhang, Int. J. Hydrogen Energy 40, 7093 (2015)

[28] Y.M. Li, Y.H. Zhang, H.P. Ren, Acta Metall. Sin. (Engl. Lett.) (2018). https://doi.org/10.1007/s40195-017-0696-y

[29] J.J. Liu, Y. Li, D. Han, S.Q. Yang, X.C. Chen, L. Zhang, S.M. Han, J. Power Sources 300, 77 (2015)

[30] J. Nakamura, K. Iwase, H. Hayakawa, Y. Nakamura, E. Akiba, J. Phys. Chem. C 113, 5853 (2009)

[31] T.T. Zhai, T. Yang, Z.M. Yuan, S. Xu, W.G. Bu, Y. Qi, Y.H. Zhang, J. Alloys Compd. 639, 15 (2015)

[32] K. Young, T. Ouchi, H. Shen, L.A. Bendersky, Int. J. Hydrog. Energy 40, 8941 (2015)

[33] M. Balogun, Z.M. Wang, H.G. Zhang, Q.R. Yao, J.Q. Deng, H.Y. Zhou, J. Alloys Compd. 579, 438 (2013)

[34] Q.R. Yao, H.Y. Zhou, Z.M. Wang, S.K. Pan, G.H. Rao, J. Alloys Compd. 606, 81 (2014)

[35] J. Lin, Y. Cheng, F. Liang, L.S. Sun, D.M. Yin, Y.M. Wu, L.M. Wang, Int. J. Hydrog. Energy 39, 13231 (2014)

[36] X.Q. Shen, Y.G. Chen, M.D. Tao, C.L. Wu, G. Deng, Z.Z. Kang, Int. J. Hydrog. Energy 34, 3395 (2009)

[37] Z.R. Jia, L. Zhang, Y.M. Zhao, J. Cao, Y. Li, Z.T. Dong, W.F. Wang, S.M. Han, J. Power Sources 188, 371 (2017)

[38] E. Axinte, Mater. Des. 35, 518 (2012)

[39] Y.G. Kim, J.Y. Lee, J. Alloys Compd. 187, 1 (1992)

[40] K. Aoki, T. Masumoto, J. Alloys Compd. 231, 20 (1995)

[41] K. Aoki, Mater. Sci. Eng. A 304-306, 45 (2001)

[42] K. Young, T. Ouchi, J. Nei, J.M. Koch, Y.L. Lien, Batteries 3, 34 (2017)

[43] H.Z. Yan, W. Xiong, L. Wang, B.Q. Li, J. Li, X. Zhao, Int. J. Hydrog. Energy 42, 2257 (2017)

[44] L.Z. Ouyang, J.L. Huang, H. Wang, J.W. Liu, M. Zhu, Mater. Chem. Phys. 200, 164 (2017)

[45] Z.J. Cao, L.Z. Ouyang, L.L. Li, Y.S. Lu, H. Wang, J.W. Liu, D. Min, Y.W. Chen, F.M. Xiao, T. Sun, R.H. Tang, M. Zhu, Int. J. Hydrog. Energy 40, 451 (2015)

[46] L.Z. Ouyang, T.H. Yang, M. Zhu, D. Min, T.Z. Luo, H. Wang, F.M. Xiao, R.H. Tang, J. Alloys Compd. 735, 98 (2018)

[47] Z.J. Cao, L.Z. Ouyang, H. Wang, J.W. Liu, D.L. Sun, Q.A. Zhang, M. Zhu, J. Alloys Compd. 608, 14 (2014)

[48] Y.M. Zhao, L. Zhang, Y.Q. Ding, J. Cao, Z.R. Jia, C.P. Ma, Y. Li, S.M. Han, J. Alloys Compd. 649, 1089 (2017)

[49] W. Xiong, H.Z. Yan, L. Wang, V. Verbetsky, X. Zhao, S. Mitrokhin, B.Q. Li, J. Li, Y. Wang, Int. J. Hydrogen Energy 42, 10131 (2017)

[50] J.J. Liu, Y.K. Yan, H.H. Cheng, S.M. Han, Y.F. Lv, K. Li, C. Lu, J. Power Sources 351, 26 (2017)

[51] F.L. Zhang, Y.C. Luo, J.P. Chen, R.X. Yan, L. Kang, J.H. Chen, J. Power Sources 150, 247 (2005)

[52] J.J. Liu, S.M. Han, Y. Li, J.L. Zhang, Y.M. Zhao, L.D. Che, Int. J. Hydrog. Energy 38, 14903 (2013)

[53] J.J. Liu, S.M. Han, D. Han, Y. Li, S.Q. Yang, L. Zhang, Y.M. Zhao, J. Power Sources 287, 237 (2015)

[54] C.J. Xue, L. Zhang, Y.P. Fan, G.X. Fan, B.Z. Liu, S.M. Han, Int. J. Hydrog. Energy 42, 6051 (2017)

[55] J.J. Liu, S.M. Han, Y. Li, X. Zhao, S.Q. Yang, Y.M. Zhao, Int. J. Hydrog. Energy 40, 1116 (2015)

[56] Y.H. Zhang, X.P. Dong, S.H. Guo, G.Q. Wang, J.Y. Ren, X.L. Wang, Int. J. Hydrog. Energy 31, 63 (2006)

[57] H.P. Ren, Y.H. Zhang, B.W. Li, X.P. Dong, X.L. Zhao, X.L. Wang, Mater. Charact. 58, 289 (2007)

[58] Y.H. Zhang, B.W. Li, H.P. Ren, Y. Cai, X.P. Dong, X.L. Wang, Int. J. Hydrog. Energy 32, 4627 (2007)

[59] Y.H. Zhang, Y. Cai, C. Zhao, T.T. Zhai, G.G. Zhang, D.L. Zhao, Int. J. Hydrog. Energy 37, 14590 (2012)

[60] Y.M. Li, Y.H. Zhang, H.P. Ren, Z.C. Liu, H. Sun, Int. J. Hydrog. Energy 41, 18571 (2016) 